\title{
Hybride stadsregionaal bestuur belicht: effectiviteit en legitimiteit in vier grootstedelijke gebieden ${ }^{*}$
}

\author{
Linze Schaap, Carlo Colombo, Maaike Damen \& Niels Karsten
}

\begin{abstract}
Dit artikel bevat een analyse van de effectiviteit en legitimiteit van bestuursvormen in vier Europese stadsregio's met duidelijke kenmerken van hybride bestuur, dat wil zeggen met zowel private als publieke kenmerken. Daarmee wordt in Berlijn, Eindhoven, Kopenhagen-Malmö en Zürich beoogd het probleemoplossend vermogen van het regionaal bestuur te vergroten en 'slim' te besturen in een complexe en gelaagde omgeving. Elk van de vier steden is op haar eigen manier op zoek naar effectieve verbindingen met private en maatschappelijke partijen; de legitimiteitsvraag blijft onderbelicht. Hybride bestuursvormen dragen risico's in zich ten aanzien van zowel effectiviteit en legitimiteit, maar bieden ook nieuwe mogelijkheden voor goed bestuur. 'Hybride' en 'slim' gaan dus niet noodzakelijkerwijs samen, maar sluiten elkaar ook niet uit.
\end{abstract}

\section{Introductie}

Stadsregionale gebieden worden in toenemende mate gezien als brandpunten voor sociale en technologische innovatie, in antwoord op economische, sociaalmaatschappelijke en ecologische uitdagingen (OECD, 2011). Dat brengt belangrijke bestuurlijke uitdagingen met zich mee. Immers, bij het besturen van regionale gebieden zijn veelal verschillende bestuurlijke partners betrokken die elk op een andere territoriale basis georganiseerd zijn. Dat komt doordat functioneel samenhangende gebieden, zoals met betrekking tot arbeid, mobiliteit, economie en veiligheid, vaak niet samenvallen met bestuurlijke grenzen, niet in de laatste plaats doordat elk maatschappelijk vraagstuk zijn eigen schaal kent (Dahl \& Tufte, 1973; Skelcher, Sullivan \& Jeffares, 2013). En voor zover al duidelijk is waar de grenzen van een functioneel gebied liggen, hebben die voor private partijen - die eveneens een belangrijke rol spelen - niet altijd dezelfde betekenis als voor bestuurlijke actoren. Het in een regionale context goed kunnen inspelen op maatschappelijke uitdagingen vraagt daarom om innovatieve vormen van organisatie en samenwerking die niet alleen bestuurlijke eenheden maar ook maatschappelijke partners, bedrijven en - soms - burgers incorporeren, voorbij

* De auteurs zijn verbonden aan het Tilburg Center for Regional Law and Governance, Tilburg University: dr. L. Schaap als universitair hoofddocent bestuurskunde en projectleider van het onderzoek waar dit artikel uit voortvloeit, dr. C.M. Colombo en dr. M.J. Damen-Koedijk als postdocs en dr. N. Karsten, Msc MA als universitair docent. Dit artikel is gebaseerd op het door NWO en de provincie Noord-Brabant gefinancierde onderzoeksproject 'Smart Transformations in City-regional Law and Governance'. 
bestaande arrangementen. Wij noemen deze ook wel 'hybride bestuursvormen', omdat ze private en publieke grondslagen voor besturen met elkaar combineren (Engel, 2001). Juist in stedelijke regio's worden dergelijke traditionele scheidslijnen uitgedaagd (Levelt \& Metze, 2014). In dit artikel leggen we enkele hybride vormen van stadsregionaal bestuur langs twee centrale meetlatten van goed bestuur: effectiviteit en legitimiteit (Dahl \& Tufte, 1973; Hendriks, 2010; Van den Dool, Hendriks, Gianoli \& Schaap, 2015). Daarmee duiden we op respectievelijk het vermogen om strategisch beleid te maken dat het handelen van de samenwerkende partijen coördineert, en het draagvlak dat bestaat voor de organisatie als zodanig, bij zowel de samenwerkende partijen als externe actoren.

\section{Het evalueren van hybride stadsregionaal bestuur}

Van hybride bestuursvormen wordt, in termen van goed bestuur, nogal wat verwacht. Ze zouden onder andere een groter probleemoplossend vermogen hebben dan traditionele vormen van bestuur (Harrison \& Hoyler, 2014) en beter in staat zijn antwoorden te vinden op hedendaagse complexe en multi-level maatschappelijke vraagstukken. Al met al zou hybride bestuur leiden tot de noodzakelijke bestuurskracht voor het besturen van complexe stadsregio's, en dus kunnen worden aangeduid als een 'slimme' manier van besturen.

Maar hybride bestuur zou evenzeer minder effectief kunnen zijn in het duurzaam aanpakken van stadsregionale vraagstukken dan verwacht. Doordat zeer verschillende actoren die elk hun eigen logica en identiteit hebben aan stadsregionaal bestuur deelnemen, kunnen conflicten ontstaan die de effectiviteit van het hybride bestuursmodel aantasten (Lemos \& Agrawal, 2006). Hybride bestuur kan ook de decentrale democratie aantasten. Weliswaar kan de betrokkenheid van private actoren en het gebruik van samenwerkingsvormen de traditionele representatieve democratie zinvol aanvullen, maar het ontbreekt hybride vormen van bestuur vaak aan directe democratische legitimatie (Engel, 2001; Skelcher et al., 2013).

In de volgende paragraaf bespreken wij vier casus van hybride stadsregionaal bestuur aan de hand van deze maatstaven. De casus zijn geselecteerd uit landen die tot soortgelijke staatstradities behoren (Rijnlandse en Noordse), met hun karaktertrekken van sterk decentraal bestuur, publiek-private samenwerking, corporatisme en consensuspolitiek (Loughlin, Hendriks, \& Lidström, 2011). Daarmee beogen we een deel van de contextgevoeligheid uit te sluiten. Daarbinnen is gekozen voor variëteit met betrekking tot de mate en vorm van hybriditeit. Op basis van een inventariserende literatuurstudie zijn casus geselecteerd uit Berlijn, Eindhoven, Kopenhagen-Malmö en Zürich. In het onderzoek is gebruikgemaakt van diverse bronnen: academische literatuur, beleidsdocumenten, interviews en 'Lab'-bijeenkomsten met zowel onderzoekers als strategische beleidsmakers uit de vier steden. 


\section{Vier casus van hybride stadsregionaal bestuur}

Quartiersmanagement Stadstaat Berlijn: veelheid van multi-level en publiek-private relaties

De eerste casus is het stadsregionale systeem van het Berlijnse buurtbestuur dat onderdeel is van het federale/Länder programma 'Soziale Stadt' (BMVBS, 2008). Het richt zich op het tegengaan van sociaal-ruimtelijke segregatie. Vanuit het programma worden lokale activiteiten ondersteund met subsidie en worden burgers actief betrokken bij het projectmanagement. Het hybride karakter van dit bestuursmodel zit vooral in het feit dat private partijen niet alleen via een uitbestedingsprocedure door het Land Berlijn worden ingehuurd om burgerparticipatie te organiseren, maar ook zelf geacht worden wijkbeleid te ontwikkelen en uit te voeren, in samenspraak met bewoners.

\section{Brainport Eindhoven: een triple-helix samenwerking}

Brainport Eindhoven is een voorbeeld van een triple-helix structuur, waarin bedrijfsleven, kennisinstellingen en regionale overheden op basis van gelijkwaardigheid samenwerken aan de regionale innovatieagenda. Deze gelijkwaardigheid komt vooral tot uiting in Stichting Brainport, waarin alle partijen zijn vertegenwoordigd, en waarin de besluitvorming over de regionale ontwikkelingsstrategie plaatsvindt (Schaap \& Van Ostaaijen, 2015). Daarnaast staat Brainport Development, het private ontwikkelingsbedrijf van de tripartiete samenwerking, waarvan de gemeenten de belangrijkste aandeelhouders zijn.

\section{Greater Copenhagen and Skåne Committee (GCSC): landsgrensoverschrijdende publieke samenwerking}

Het GCSC-samenwerkingsverband in de Øresundregio omvat drie regio's, twee in Denemarken (Hovedstaden en Sjælland) en één in Zweden (Skåne). Het richt zich op de gezamenlijke marketing van de regio Greater Copenhagen, een sterke infrastructuur, het aantrekken van investeerders, toeristen, bedrijven en talenten, en duurzame ontwikkeling (GCSC, 2017). In het privaatrechtelijke samenwerkingsverband participeren (alle) subnationale overheidsinstanties uit de drie regio's. Deze samenwerking bestempelen we als hybride, omdat zij de territoriale grenzen van de verschillende besturen overstijgt en private partijen betrokken zijn bij het opzetten en uitvoeren van specifieke projecten. Bovendien is een aantal private en maatschappelijke partijen op ad-hocbasis betrokken bij de beleidsvoorbereiding.

\section{Verein Metropolitanraum Zürich (VMZ): publieke samenwerking in private vorm}

De VMZ is een samenwerkingsverband gericht op het coördineren van beleid op het gebied van regionale economische ontwikkeling, transport, maatschappij en ruimtelijke ontwikkeling (Nüssli, 2015). Daartoe participeert ruim de helft van de regionale overheidsinstanties op vrijwillige basis in de vereniging: op dit moment ongeveer 120 steden en gemeenten en acht kantons. Hoewel in de samenwerking vrijwel alleen publieke organisaties participeren, kan deze toch als hybride worden aangemerkt: de vereniging kent een privaatrechtelijke grondslag, wordt 
Tabel 1 Overzicht van de actoren en het hybride karakter van de vier casus

\begin{tabular}{|c|c|c|c|c|}
\hline $\begin{array}{l}\text { Betrokken } \\
\text { actoren } \\
\text { Stadsregio }\end{array}$ & Private partijen & $\begin{array}{l}\text { Maatschappe- } \\
\text { lijke en/of ken- } \\
\text { nisorganisaties }\end{array}$ & Burgers & $\begin{array}{c}\text { Hybride karak- } \\
\text { ter }\end{array}$ \\
\hline $\begin{array}{l}\text { Quartiersmanage- } \\
\text { ment Berlijn }\end{array}$ & $\begin{array}{l}\text { Private gecontrac- } \\
\text { teerde ontwikke- } \\
\text { laar en uitvoerder } \\
\text { van wijkbeleid }\end{array}$ & $\begin{array}{l}\text { Adviesrol over } \\
\text { concrete pro- } \\
\text { jecten via partici- } \\
\text { patie in buurtraad }\end{array}$ & $\begin{array}{l}\text { Adviesrol over } \\
\text { concrete pro- } \\
\text { jecten via partici- } \\
\text { patie in buurtraad }\end{array}$ & $\begin{array}{l}\text { Combinatie van de } \\
\text { logica van aanbe- } \\
\text { steden met de } \\
\text { actieve betrokken- } \\
\text { heid van organisa- } \\
\text { ties en burgers }\end{array}$ \\
\hline $\begin{array}{l}\text { Brainport Eindho- } \\
\text { ven }\end{array}$ & $\begin{array}{l}\text { Formele rol in tri- } \\
\text { ple-helix besluit- } \\
\text { vorming over } \\
\text { strategisch regio- } \\
\text { beleid en private } \\
\text { uitvoeringsorgani- } \\
\text { satie }\end{array}$ & $\begin{array}{l}\text { Formele rol voor } \\
\text { kennisinstellingen } \\
\text { in triple-helix } \\
\text { besluitvorming } \\
\text { over strategisch } \\
\text { regiobeleid }\end{array}$ & $\begin{array}{l}\text { Als eindgebruiker } \\
\text { betrokken in pro- } \\
\text { jecten, maar geen } \\
\text { rol het het } \\
\text { bestuur van de } \\
\text { regio }\end{array}$ & $\begin{array}{c}\text { Gelijkwaardige } \\
\text { samenwerking tus- } \\
\text { sen private par- } \\
\text { tijen, kennisinstel- } \\
\text { lingen en overhe- } \\
\text { den }\end{array}$ \\
\hline $\begin{array}{l}\text { Greater Copen- } \\
\text { hagen \& Skåne } \\
\text { Committee }\end{array}$ & $\begin{array}{l}\text { Op ad-hocbasis } \\
\text { betrokken bij de } \\
\text { beleidsvoorberei- } \\
\text { ding en het opzet- } \\
\text { ten en uitvoeren } \\
\text { van specifieke } \\
\text { projecten }\end{array}$ & $\begin{array}{l}\text { Op ad-hocbasis } \\
\text { betrokken bij de } \\
\text { beleidsvoorberei- } \\
\text { ding en het opzet- } \\
\text { ten en uitvoeren } \\
\text { van specifieke } \\
\text { projecten }\end{array}$ & Geen rol & $\begin{array}{l}\text { Publieke samen- } \\
\text { werking met ad } \\
\text { hoc private betrok- } \\
\text { kenheid in de } \\
\text { beleidsuitvoering }\end{array}$ \\
\hline $\begin{array}{l}\text { Verein Metropoli- } \\
\text { tanraum Zürich }\end{array}$ & $\begin{array}{l}\text { Privaatrechtelijke } \\
\text { grondslag, privaat } \\
\text { secretariaat, uit- } \\
\text { bestedingsproce- } \\
\text { dure voor pro- } \\
\text { jecten }\end{array}$ & $\begin{array}{c}\text { Verbonden leden } \\
\text { en reflectiegroep } \\
\text { met zeer } \\
\text { beperkte rol }\end{array}$ & Geen rol & $\begin{array}{l}\text { Publiek-publieke } \\
\text { samenwerking in } \\
\text { de vorm van een } \\
\text { private organisatie, } \\
\text { met verschillende } \\
\text { private kenmerken }\end{array}$ \\
\hline
\end{tabular}

ondersteund door een privaat secretariaat en kent een aantal private verbonden leden. Bovendien kunnen private partijen, in een uitbestedingsprocedure, projectvoorstellen indienen. En er is een, overigens weinig actieve, 'echokamer', waarin maatschappelijke partners reflecteren op de activiteiten van de VMZ.

Tabel 1 bevat een overzicht van de betrokkenheid van de actoren en het hybride karakter van de verschillende modellen.

\section{Effectiviteit en legitimiteit van hybride arrangementen}

Leggen we deze veelzijdige bestuursmodellen langs de twee door Hendriks (2010) aangedragen maatstaven van goed bestuur, namelijk effectiviteit en legitimiteit, dan kunnen we vaststellen dat hybriditeit zowel een kracht als een zwakte kan zijn en dat de precieze uitwerking ervan sterk afhankelijk is van de context waarin de hybriditeit zich manifesteert. 


\section{Effectiviteit}

Verschillende factoren beïnvloeden de effectiviteit van de samenwerking. In Berlijn is de uitvoering van het beleid via een uitbestedingsprocedure in handen gegeven van private partijen. Daardoor kan worden geput uit hun jarenlange expertise met burgerparticipatie en wijkontwikkelingsbeleid, waarover het stadsbestuur niet beschikt. De private partijen ontwikkelen het wijkbeleid en het burgerparticipatiebeleid, waarmee ze een sterk publieke rol hebben. In de praktijk blijkt dat het lokaal ontwikkelde beleid nogal eens botst met de visie van het stadsbestuur; dat kan de effectiviteit van de beleidsuitvoering aantasten. Bovendien is het voor Quartiermanagers regelmatig de vraag of zij de belangen vertegenwoordigen van hun opdrachtgever (het stadsbestuur) of die van de wijkbewoners. Als hybride organisatie valt het Quartiersmanagement in feite overal tussen. 'Ze horen feitelijk bij niemand', aldus een respondent.

Dat is in de grootstedelijke Brainport-samenwerking rondom Eindhoven wezenlijk anders. Private partijen, kennisinstellingen en overheden zijn gelijkwaardige partners bij de ontwikkeling van het strategisch regiobeleid en de privaatrechtelijke rechtsvorm (de stichting) biedt de mogelijkheid om onderling strategische afspraken te maken. De implementatie daarvan wordt vervolgens overgedragen aan ontwikkelingsbedrijf Brainport Development, waarmee stevige uitvoeringscapaciteit beschikbaar is. Deze bestuursvorm wordt als zeer effectief gezien op het terrein van economische ontwikkeling en innovatie. De verbintenis met de stichting en het feit dat gemeenten daarin de belangrijkste aandeelhouders zijn, zorgen in de ogen van betrokkenen over het algemeen voor voldoende politiek commitment. Tegelijk zien we klassieke agency problems ontstaan in de zin dat de beleidsuitvoering in Brainport Development niet altijd een een-op-een vertaling is van het strategisch beleid dat in de stichting wordt bepaald.

Anders dan bij Brainport is in het bestuursmodel van de GCSC de implementatiecapaciteit decentraal georganiseerd; gemeenten worden geacht die zelf in te brengen. Die keuze is ingegeven door recente ervaringen. De voorganger van de GCSC, het Øresund Committee, had wel een aanzienlijke uitvoeringscapaciteit en kwam als gevolg daarvan op afstand te staan van de deelnemende gemeenten en regio's, waardoor het noodzakelijke politieke commitment wegebde. De nieuwe organisatievorm heeft zich bewezen met onder andere een mobiliteitshandvest, maar ontbeert naar eigen zeggen structurele betrokkenheid en inbedding van maatschappelijke en private partijen.

In Zürich wordt dan weer getwijfeld aan het nut dáárvan. In de constitutionele context van Zwitserland, met zijn drie bestuurslagen (federaal, kantonaal en gemeentelijk niveau) en sterke decentrale autonomie, wordt in strategisch regiobeleid in de VMZ juist niet ingezet op nauwe samenwerking met private en maatschappelijke partijen. Betrokkenen ervaren daarvoor nauwelijks ruimte, vanwege het primaat van de politiek. Wel zijn alternatieve vormen van hybriditeit gevonden, in onder andere het private secretariaat - dat politiek neutraler kan optreden - en in de mogelijkheid voor private en maatschappelijke partijen om projectvoorstellen in te dienen in een uitbestedingsprocedure. Zo blijft de organisatie 'contact houden met wat er buiten de publieke organisaties speelt', zo stelden verschillende respondenten vast. Tegelijk is er van echte governance vanuit de VMZ 
nauwelijks sprake. De gekozen privaatrechtelijke samenwerkingsvorm op basis van vrijwilligheid biedt weinig houvast voor bindende strategische beleidsvorming.

\section{Legitimiteit}

Hybride vormen van bestuur brengen ook legitimiteitsvragen met zich mee. Immers, waar publieke organisaties in het bestaande stelsel veelal kunnen leunen op directe democratische legitimatie via verkiezingen, geldt dat zelden voor hybride bestuursvormen. Daarin ontbreken vaak de democratische middelen voor derden om (directe of indirecte) inbreng te hebben of om de participerende publieke organisaties effectief ter verantwoording te roepen. Om die reden gaan we hieronder na of en hoe de vier bestuursmodellen omgaan met het vraagstuk van legitimiteit.

In Berlijn wordt de traditionele, top-down representatieve democratie aangevuld met grassroots-democratie, door de actieve rol van burgers en maatschappelijke organisaties in de besluitvormingsprocedures. Democratische legitimiteit wordt dus langs twee lijnen gewaarborgd. Dit leidt soms tot spanningen tussen de verschillende mandaten, maar dat is vanuit het oogpunt van democratische legitimiteit niet per definitie slecht. Immers, de botsingen kunnen gesprekken op gang brengen over wat het algemeen belang is en wie dat vertegenwoordigen (Hendriks, 2010).

In Eindhoven speelt het legitimiteitsvraagstuk vooral een rol op het niveau van de individuele (vaak kleinere) gemeenten, waarbij regelmatig de vraag is in hoeverre zij daadwerkelijk invloed hebben op en kunnen bijdragen aan de ontwikkeling van Brainport en of er effectieve verantwoordingsmechanismen bestaan. Het hybride karakter van de samenwerking maakt immers dat die op afstand staat van de besluitvorming in gemeenteraden. Het feit echter, dat de regio Eindhoven als succesvol wordt beoordeeld, maakt dat veel discussie over de legitimiteit ervan in de kiem wordt gesmoord. De outputlegitimiteit van Brainport lijkt in die zin sterker ontwikkeld dan de inputlegitimiteit. Tegelijk zegt Brainport te werken aan het 'inclusiever' maken van de regio en van een triple-helix naar een multi-helix bestuursmodel te gaan en onder andere burgers te betrekken bij de samenwerking (Brainport Development, 2015). In de feitelijke uitwerking van die nieuwe strategie blijken burgers echter vooral als eindgebruiker van innovaties te worden beschouwd; van betrokkenheid bij besluitvorming is nauwelijks sprake.

Ook bij de besluitvorming binnen de GCSC zijn geen burgers betrokken. De democratische legitimiteit van de organisatie, die primair rust op indirecte legitimatie via de gemeenteraden en burgemeesters, wordt dan ook als zwakte aangeduid. Tegelijk wordt dit niet als een belangrijk of urgent probleem ervaren. Dat komt ook doordat de regionale samenwerking enkele successen kent in het beïnvloeden van de nationale overheden. Ook hier wordt outputlegitimiteit dus boven inputlegitimiteit gesteld.

Ook in Zürich wordt de legitimiteit van de organisatie primair gewaarborgd door indirecte vertegenwoordiging via de bestuurders van de gemeenten en kantons die de burgers van deze gebieden vertegenwoordigen. Tegelijkertijd ziet een aan- 
Tabel 2 Overzicht van de effectiviteit en legitimiteit van de vier casus

\begin{tabular}{|c|c|c|}
\hline $\begin{array}{l}\text { Beoordelingscriteria } \\
\text { Stadsregio }\end{array}$ & Effectiviteit & Legitimiteit \\
\hline $\begin{array}{l}\text { Quartiersmanagement } \\
\text { Berlijn }\end{array}$ & $\begin{array}{l}\text { + inhuren van specifieke } \\
\text { expertise } \\
\text { - botsende mandaten }\end{array}$ & $\begin{array}{l}\text { + combinatie van represen- } \\
\text { tatieve en participatieve } \\
\text { democratie }\end{array}$ \\
\hline Brainport Eindhoven & $\begin{array}{l}\text { + krachtenbundeling pri- } \\
\text { vate, maatschappelijke en } \\
\text { publieke partijen } \\
+ \text { stevige uitvoeringsorgani- } \\
\text { satie met politiek commit- } \\
\text { ment } \\
\text { - agency problems }\end{array}$ & $\begin{array}{l}\text { - succesvolle samenwerking } \\
\text { smoort legitimiteitsdiscus- } \\
\text { sie } \\
\text { - weinig directe betrokken- } \\
\text { heid gemeenteraden }\end{array}$ \\
\hline $\begin{array}{l}\text { Greater Copenhagen \& } \\
\text { Skåne Committee }\end{array}$ & $\begin{array}{l}\text { +/- lokaal organiseren van } \\
\text { uitvoeringscapaciteit } \\
\text { - minimale rol private en } \\
\text { maatschappelijke partijen }\end{array}$ & $\begin{array}{l}\text { - succesvolle samenwerking } \\
\text { smoort legitimiteitsdiscus- } \\
\text { sie } \\
\text { - indirecte legitimatie }\end{array}$ \\
\hline $\begin{array}{l}\text { Verein Metropolitanraum } \\
\text { Zürich }\end{array}$ & $\begin{array}{l}\text { + coalition of the willing } \\
\text { - nauwelijks concrete } \\
\text { beleidsvorming }\end{array}$ & $\begin{array}{l}\text { - indirecte legitimatie en } \\
\text { gebrekkige verantwoording }\end{array}$ \\
\hline
\end{tabular}

tal betrokkenen het feit dat er nauwelijks verantwoording wordt afgelegd over de activiteiten van de VMZ aan de gemeenten en kantons, als risico voor haar legitimiteit (zie ook Schwab, Kübler, \& Walti, 2001).

Dit leidt tot het overzicht van slimme oplossingen en geïdentificeerde risico's zoals weergegeven in tabel 2.

\section{Vergelijkende discussie}

In alle vier de casus zien we dat de regionale besturen op zoek zijn naar bestuursvormen die passen bij het doel van de organisatie en effectief zijn. Hybriditeit is hierin steeds een 'slim' element dat beoogt het probleemoplossend vermogen van het bestuur te vergroten door publieke, private en maatschappelijke partijen bij elkaar te brengen en door publieke en private karakteristieken te combineren. Ze krijgt in elk van de casus anders vorm. Waar in Brainport gekozen is voor een triple-helix, wordt een dergelijke organisatievorm voor de VMZ misschien wenselijk, maar niet haalbaar geacht, gelet op het belang van lokale autonomie en het primaat van de politiek. Lichte en vrijwillige intergemeentelijke samenwerking lijkt daardoor een van de weinige mogelijkheden om tot een vorm van regionaal bestuur te komen (Plüss \& Schenkel, 2014). Daarbinnen zoekt men naar elementen van hybride bestuur, om zo de verbinding met de samenleving te houden. Ook de GCSC is op dit punt nog zoekende: betrokkenen zien het belang van het betrekken van private partijen, maar komen vooralsnog niet verder dan ad-hocbetrokkenheid relatief laag in de organisatie. De publieke logica blijft daar behoor- 
lijk dominant. Dat geldt ook in Berlijn, waar gewerkt wordt met een uitbestedingsprocedure waarin het private wijkmanagement wel wordt aangeduid als 'de verlengde arm van de Senaat'. Die kwalificatie doet echter geen recht aan het hybride karakter van de bestuursvorm, waarin een private partij publiek beleid ontwikkelt en ook een verantwoordelijkheid draagt om burgers bij het bestuur te betrekken. Dat leidt wel tot botsende mandaten en tot vragen over de rol van een hybride tussenorganisatie zoals het Quartiersmanagement. Soms beperkt dat de effectiviteit van het bestuursmodel, maar er gaat ook een kracht van uit, doordat de organisatie de flexibiliteit heeft van een private partij bij het uitvoeren van publiek beleid. Bovendien is de legitimiteit van het Quartiersmanagement relatief goed gewaarborgd. Dat heeft deels met het schaalniveau te maken, maar ook met de gekozen benadering. In de andere drie stadsregio's wordt outputlegitimiteit in hoge mate boven inputlegitimiteit gesteld, zeker daar waar die laatste het gevolg zou kunnen zijn van directe betrokkenheid van burgers. In Berlijn is men er echter van overtuigd dat de effectiviteit van het beleid staat of valt met de legitimiteit ervan (zie ook Hendriks, 2010). In de andere drie stadsregio's bestaat die overtuiging veel minder en wordt het legitimiteitsprobleem niet zo gevoeld. Tegelijk wordt, vooral in Eindhoven en in de GCSC, en in mindere mate in Zürich, wel naar verbindingen met burgers en maatschappelijke organisaties gezocht die verder gaan dan nu. Die pogingen zijn vooralsnog echter weinig effectief, zoals blijkt uit de weinig overtuigende manier waarop Brainport omgaat met het idee van een multi-helix en Zürichs poging om een reflectiegroep van maatschappelijke organisaties levend te houden. Tegelijk zien we in beide regio's ook nieuwe initiatieven ontstaan om passende vormen van hybride bestuursvormen te vinden, zoals de mogelijkheid in Zürich voor burgers en het maatschappelijk middenveld om projectvoorstellen in te dienen en het voornemen om future labs te organiseren waarin zij kunnen meedenken over de toekomst van de stadsregio. Dat soort initiatieven moet zich echter nog bewijzen.

\section{Conclusie}

Elk van de vier stedelijke regio's zoekt naar effectieve en legitieme vormen van stadsregionaal bestuur die passen bij de lokale context, waarbij hybriditeit gebruikt wordt als instrument om het probleemoplossend vermogen te vergroten. Outputlegitimiteit gaat daarbij al snel boven inputlegitimiteit. Dat wil zeggen: de resultaten die het stadsregionale bestuur behaalt voor economie en samenleving, worden als belangrijker gezien dan de vraag of vertegenwoordigers van die samenleving invloed hebben op of betrokken zijn bij de besluitvorming van de stedelijke regio. Dat laatste gebeurt in ons type democratie traditioneel in de vorm van gekozen volksvertegenwoordigers. En de perceptie dat de representatieve democratie de enige bron van democratische legitimiteit is, blijft in alle vier de stedelijke regio's, deels met uitzondering van Brainport, betrekkelijk dominant. Tegelijkertijd spelen de vertegenwoordigende organen veelal een slechts marginale rol. Een andere manier om de inputlegitimiteit te versterken is door burgers en/of maatschappelijke belangenvertegenwoordigers een rol te geven in 
het verwoorden van maatschappelijke voorkeuren. Dat eerste wordt in de vier casus vooral met de mond beleden, behalve in Berlijn, waar burgers in diverse rollen invloed kunnen hebben. Het zoeken van vruchtbare verbindingen van het stadsregionale bestuur met maatschappelijke partijen gebeurt wel en die zoektocht ziet er in elke stadsregio anders uit. Tegelijkertijd is daar nog veel te winnen: het betrekken van die partijen is soms nogal selectief en eenzijdig en de betrokkenheid is zelden een invloedrijke (met uitzondering van Brainport Eindhoven). Dat laatste is dan vooral vanwege het normatieve uitgangspunt van de representatieve democratie. Scherp gesteld: legitimiteit van het stadsregionale bestuur wordt veelal amper als een probleem gezien, betrokkenen nemen aan dat kan worden vertrouwd op de steun van de bestaande volksvertegenwoordigende organen.

Het vinden van echt hybride bestuursvormen is nog een belangrijke uitdaging voor practitioners. Een combinatie van publieke en private logica's voor het effectief maken van de regio is niet voldoende. Ook zal moeten worden gezocht naar een variatie van bronnen voor legitimiteit; het leunen op betrokkenheid van bestaande volksvertegenwoordigingen alleen is riskant. Immers: verkiezingen als zodanig zijn al niet feilloos voor het vertalen van maatschappelijke voorkeuren en dat wordt nog erger als er voor het stadsregionale bestuur zelf geen verkiezingen zijn. Op het stadsregionale niveau ligt een interessante kans op het vermaatschappelijken van de democratie: misschien wel juist daar is het mogelijk en zinvol vertegenwoordigers van maatschappelijke belangen (per vraagstuk of beleidsdomein) een invloedrijke rol te geven. $\mathrm{Zij}$ zullen dan niet alleen relevante kennis en inzichten inbrengen, maar ook maatschappelijke steun. En misschien kunnen we dan pas echt spreken over slim bestuur: bundeling van publieke en private krachten en logica's niet alleen voor effectieve beslissingen, maar ook voor houdbare, haalbare en legitieme.

\section{Literatuur}

BMVBS. (2008). Status Report: The Programme 'Social City'. Berlijn: Bundesministerium für Verkehr, Bau und Stadtentwicklung.

Brainport Development. (2015). Brainport next generation: revised strategy. Eindhoven: Brainport Development.

Dahl, R.A., \& Tufte, E.R. (1973). Size and democracy. Stanford: Stanford University Press.

Dool, L. van den, Hendriks, F., Gianoli, A., \& Schaap, L. (2015). The quest for good urban governance. Wiesbaden: Springer VS.

Engel, C. (2001). Hybrid governance across national jurisdictions as a challenge to constitutional law. European Business Organization Law Review, 2(3-4), 569-583.

GCSC. (2017). Greater Copenhagen Action Plan 2017. Kopenhagen: Greater Copenhagen \& Skåne Committee.

Harrison, J., \& Hoyler, M. (2014). Governing the new metropolis. Urban Studies, 51(11), 2249-2266.

Hendriks, F. (2010). Vital democracy: A theory of democracy in action. Oxford: Oxford University Press. 
Lemos, M.C., \& Agrawal, A. (2006). Environmental governance. AnnualReview of Environment and Resources, 31, 297-325.

Levelt, M., \& Metze, T. (2014). The legitimacy of regional governance networks: Gaining credibility in the shadow of hierarchy. Urban Studies, 51(11), 2371-2386.

Loughlin, J., Hendriks, F., \& Lidström, A. (2011). The Oxford handbook of local and regional democracy in Europe. Oxford: Oxford University Press.

Nüssli, R. (2015). Auf dem Weg zu einer metropolitanen Regulation? Der Verein Metropolitanraum Zürich. Geographica Helvetica, 70(1), 11-25.

OECD. (2011). Regions and innovation policy. Parijs: OECD Publishing.

Plüss, L., \& Schenkel, W. (2014). Urban policies on diversity in Zürich. Zürich: Synergo.

Schaap, L., \& Ostaaijen, J. van. (2015). Good multi-level governance: Brainport Eindhoven. In L. van den Dool, F. Hendriks, A. Gianoli, \& L. Schaap (red.), The quest for good urban governance: Theoretical reflections and international practices (pp. 147-163). Wiesbaden: Springer VS.

Schwab, B., Kübler, D., \& Walti, S. (2001). Metropolitan governance and democracy in Switzerland: An attempt of operationalisation and an empirical assessment. Paper ECPR Joint Session, Grenoble.

Skelcher, C., Sullivan, H., \& Jeffares, S. (2013). Hybrid governance in European cities: Neighbourhood, migration, and democracy. London: Palgrave Macmillan. 